\title{
Covered Interest Rate Parity in Emerging Markets
}

\author{
Frank S. Skinner
}

Professor of Finance, School of Management, University of Surrey, Guildford, Surrey, GU2 7XH, Tel +44 (0) 148368 6364, Fax +44 (0) 148368 6346, E-Mail F.Skinner@surrey.ac.uk.

\begin{abstract}
Andrew Mason
Lecture of Finance, School of Management, University of Surrey, Guildford, Surrey, GU2 7XH, Tel +44 (0) 148368 3093, Fax +44 (0) 148368 6346, E-Mail A.Mason@ surrey.ac.uk
\end{abstract}

\begin{abstract}
This paper finds that while covered interest rate parity holds for large and small triple A rated economies, it holds for emerging markets only for a three-month maturity. For a five-year horizon the size and frequency of violations lead to the conclusion that covered interest rate parity does not hold for longer maturities for Brazil, Chile, Russia and South Korea. Overall this paper finds that aspects of credit risk are the source of violations in CIRP in the long-term capital markets rather than transactions costs or the size of the economy.
\end{abstract}

JEL Classification: E43, G12, G15, G24

Key words: Covered Interest Rate Parity, CDS, Credit Risk. 


\section{Covered Interest Rate Parity in Emerging Markets}

\section{Introduction}

One of the fundamental tenets of international finance is covered interest rate parity CIRP. This relation says that exchange rate forward premiums (discounts) offset interest rate differentials between two sovereigns. This paper examines the role of the size of the underlying economy, transaction costs and aspects of credit risk such as volatility, market and default risk in apparent deviations in CIRP for Brazil, Chile, Russia, South Korea, Norway and the United Kingdom. Table I shows that Brazil and Russia were rated below investment grade on January 1, 2003, the date that this study commences, and all emerging economies were upgraded to some extent by October 31,2006 , the date that this study ends. ${ }^{1}$ Thus this dataset encompasses a time of fairly stable market conditions and remain untainted by the peculiarities of the recent credit crunch. Meanwhile Norway and the United Kingdom remain triple A rated throughout the sample period.

[Table 1 about here]

CIRP is well established in recent decades amongst the OECD economies for shortterm instruments. Any apparent deviations are due to transactions costs (Taylor 1987, 1989, Al-Loughani and Moosa 2002, Bhar et al. 2004) and during the extreme market conditions of 2007-08, spill over effects from counter party credit risk in the money market (Baba and Packer, 2009). Otherwise large deviations after transactions costs are rare and fleeting (Louis et al. 1999) and in recent years have virtually disappeared (Batten and Szillagyi 2010). Batten et al. (2011) find that market frictions due primarily to interest rate volatility cause the parity price to vary within a trading ban. Aliber (1973) finds that credit risk can explain violations in CIRP in the pre floating exchange rate regime in the late 1960's. Another possible reason why covered interest rate parity may not hold is tax (Levi, 1977) but Stroble's (2001) model finds that CIRP remains unaffected by capital gains tax. 
However Fong et al (2010) find large numbers of deviations in covered interest rate parity for the Hong Kong Dollar for the short term capital market. They find evidence that most of these deviations are caused by liquidity and credit risk premia yet some violations persist and can be exploited by traders able to negotiate small transaction fees. Moreover Fletcher and Taylor (1996) also find that deviations from CIRP are neither rare nor short lived in the long dated capital market. They do not provide an economic reason why this is the case however. Moreover, except for Fong et al. (2010) CIRP has not been examined for capital markets outside the OECD club. This paper seeks to address these gaps by examining CIRP for Brazil, Chile, Russia and South Korea for the short and long-term horizons.

We are also curious to see whether the size of the economy plays any role in evident violations in covered interest rate parity. For instance, the volume of foreign exchange transactions can be much smaller for modest sized economies so a lack of liquidity can lead to violations in covered interest rate parity. For this reason we also examine the United Kingdom, a large triple A rated economy and Norway, a small triple A rated economy and compare their results with the emerging market economies.

A salient feature of this study is the quality of the data. This study uses time synchronised closing daily mid, bid and ask prices for the spot currency, three month and five year forward currency exchange rates, three month interest rate, five year swap interest rate and five year credit default swap rates as reported by Bloomberg ${ }^{\text {TM }}$ as of 16:30 British Standard Time BST. Only data for instruments that were flagged by Bloomberg ${ }^{\mathrm{TM}}$ as actively traded were used. The credit default swap data allows for an examination of the role of credit risk and the bid and ask data allows for an examination of the role of transaction cost in explaining apparent deviations in CIRP.

In contrast to Fong et al (2010) this paper finds that for a three-month time horizon, deviations in CIRP are rare and are nearly fully explained by transaction costs for all four emerging markets that are examined. Any remaining violations are trivial. It is possible that our results differ from Fong et al (2010) as they use tick data rather than time synchronized end of trading day data so violations that occur during the day are exploited and arbitraged away by the close of business. However, we do find that 
deviations in CIRP can be large and frequent for the long-term capital markets. Specifically, after transactions costs Brazil, Chile, Russia and South Korea all show some degree of violation in CIRP at a five-year horizon. In contrast Norway and the UK show no evidence of violation of covered interest rate parity at either the threemonth or five year horizons. This suggests that it is credit risk rather than the size of the economy that is related to violations in CIRP. While credit default swaps CDS can help explain some of the emerging market violations, still large and frequent CIRP violations remains. In fact, when insuring deviations from CIRP with CDS the deviation from covered interest rate parity often changes sign from a large negative to a large positive thereby suggesting that CDS contracts overprice credit risk. However, like Fong et al (2010) regressing proxies for aspects of credit risk on deviations from covered interest rate parity finds that credit risk is as least part of the explanation for these violations as the largest violations of covered interest rate parity are associated with factors related to credit risk. Overall this paper finds that there are indeed violations in covered interest rate parity in the long-term capital markets but only for emerging economies. Moreover, credit risk rather than the size of the economy or transactions costs appear to be the source of these violations.

The plan for this paper is as follows. Section 2 derives CIRP for single and multiple periods and show how CIRP can be obtained even in the presence of credit risk. Section 3 introduces the data and the methodology. Section 4 presents the numerical analysis that examines the size and importance of discrepancies in covered interest rate parity. Section 5 conducts a regression analysis on discrepancies in covered interest rate parity. Section 6 then summarises and concludes.

\section{CIRP with and without credit risk}

To appreciate how credit risk impacts on CIRP, it is useful to review classic CIRP in detail. The problem faced by an investor wishing to access higher foreign interest rates $r_{f}>r$ is shown in the diagram below. Note that $S$ represents the number of foreign currency units per USD (i.e. 3 Brazilian reals to $\$ 1$ ). 


\begin{tabular}{lll}
\hline Transaction & $\mathrm{T}=0$ & $\mathrm{~T}=1$ \\
\hline $\begin{array}{l}\text { Borrow initial investment } \mathrm{S}_{0} \text { and agree to pay domestic } \\
\text { interest rate } \mathrm{r} \text { and principal with funds received from }\end{array}$ & $\mathrm{S}_{0}$ & $-\mathrm{S}_{1}(1+\mathrm{r})$ \\
foreign bonds $\mathrm{S}_{1}$ to be converted into dollars one period \\
hence.
\end{tabular}

After borrowing at the domestic interest rate $r$, converting dollars to the foreign currency $\mathrm{S}_{0}$ and investing in the foreign bonds, the investor can not be sure if a depreciation in the exchange rate one period hence $S_{1}$ will more than offset gains from investing in the higher interest rate $r_{f}$ foreign bonds. Therefore the investor will seek to hedge by selling the foreign currency one period hence $S_{1}$ forward $F_{1}$. As exchange rate risk is now eliminated and the above position has no net investment then to avoid costless and riskless arbitrage the following must hold.

$\mathrm{S}_{0}\left(1+\mathrm{r}_{\mathrm{f}}\right)-\mathrm{F}_{1}(1+\mathrm{r})=0$

and rewriting slightly,

$\frac{\mathrm{F}_{1}}{\mathrm{~S}_{0}}=\frac{\left(1+\mathrm{r}_{\mathrm{f}}\right)}{(1+\mathrm{r})}$

Equation (1a) is the classic interest rate parity condition that must hold in the absence of transactions costs. Converting (1a) into returns data by subtracting one from both sides of the equation and re-arrange the expression obtains (1b).

$\frac{\mathrm{F}_{1}-\mathrm{S}_{0}}{\mathrm{~S}_{0}}=\frac{\left(\mathrm{r}_{\mathrm{f}}-\mathrm{r}\right)}{(1+\mathrm{r})}$

Now examine CIRP when the investor is uncertain about the credit quality of the foreign bond. 


\begin{tabular}{llll}
\hline Transaction & $\mathrm{T}=\mathrm{T}=1$ (no Default) & $\mathrm{T}=1$ (Default) \\
& 0 & & \\
\hline $\begin{array}{l}\text { Borrow initial investment } \mathrm{S}_{0} \text {. Pay } \\
\text { domestic interest rate } \mathrm{r} \text { and } \\
\text { principal with funds received }\end{array}$ & $\mathrm{S}_{0}$ & $-\mathrm{F}_{1}(1+\mathrm{r})$ & $-\mathrm{F}_{1}(1+\mathrm{r})$ \\
$\begin{array}{l}\text { from foreign bonds } \mathrm{S}_{1} \text {. Hedge } \\
\text { foreign exchange risk today by } \\
\text { selling } \mathrm{S}_{1} \text { forward at exchange } \\
\text { rate } \mathrm{F}_{1} \text {. }\end{array}$ & & & \\
\hline $\begin{array}{l}\text { Convert to foreign currency }-\mathrm{S}_{0} \\
\text { and purchase foreign bonds }\end{array}$ & $-\mathrm{S}_{0}$ & $\mathrm{~S}_{0}\left(1+\mathrm{r}_{\mathrm{f}}\right)$ & \\
paying interest $\mathrm{r}_{\mathrm{f}}$. & & & $\mathrm{S}_{0}\left(1+\mathrm{r}_{\mathrm{f}}\right) \delta$ \\
\hline $\begin{array}{l}\text { Purchase default insurance } \mathrm{C} \text { on } \\
\text { the foreign bond } \mathrm{S}_{\mathrm{o}} .\end{array}$ & $-\mathrm{CS}_{0}$ & 0 & \\
Net & $-\mathrm{CS}_{0}$ & $\mathrm{~S}_{0}\left(1+\mathrm{r}_{\mathrm{f}}\right)-\mathrm{F}_{1}(1+\mathrm{r})$ & $\mathrm{S}_{0}\left(1+\mathrm{r}_{\mathrm{f}}\right)-\mathrm{F}_{1}(1+\mathrm{r})$ \\
\hline
\end{tabular}

Now the investor cannot be sure if a default of the foreign bond will eliminate promised gains from investing in the higher interest rate $r_{f}$ foreign bonds. Therefore the investor will purchase credit protection by purchasing a credit default swap $\mathrm{C}$ on the foreign bond. If the bond does not default then at maturity the cash flows are precisely the same as in the default rate free case as the CDS expires worthless. However, if the bond defaults and is now only worth $\mathrm{S}_{0}\left(1+\mathrm{r}_{\mathrm{f}}\right) \delta(0 \leq \delta \leq 1)$ then the investor receives compensation from the credit protection seller $S_{0}\left(1+r_{f}\right)(1-\delta)$ to top up the value of the investment to the promised maturity value $S_{0}\left(1+r_{f}\right)$. Therefore in the event of default payoffs from the CDS ensure that the cash flows remain the same as in the default free case.

As exchange rate and default risks are now eliminated then to avoid costless and riskless arbitrage the following must hold.

$\mathrm{S}_{0}\left(1+\mathrm{r}_{\mathrm{f}}\right)-\mathrm{F}_{1}(1+\mathrm{r})-\mathrm{CS}_{0}=0$

and rewriting slightly,

$\frac{\mathrm{F}_{1}}{\mathrm{~S}_{0}}=\frac{\left(1+\mathrm{r}_{\mathrm{f}}\right)-\mathrm{C}}{(1+\mathrm{r})}$

Equation (2a) is the classic interest rate parity condition as adjusted by default insurance $\mathrm{C}$ that must hold in the absence of transactions costs. 
Converting (2a) into returns data by subtracting one from both sides of the equation and re-arrange the expression obtains $(2 b)$.

$$
\frac{\mathrm{F}_{1}-\mathrm{S}_{0}}{\mathrm{~S}_{0}}=\frac{\left(\mathrm{r}_{\mathrm{f}}-\mathrm{r}\right)-\mathrm{C}}{(1+\mathrm{r})}
$$

Adjusting (1a) and (2a) for multiple periods is straightforward. The difference between $S_{0}$ and $F_{1}$ can represent any time frame. Borrowing in dollars and investing in the foreign currency can compound at the respective domestic and foreign interest rates for any number of time periods. Therefore the $\mathrm{N}$ period version of (1a) is simply

$$
\frac{F_{1}}{S_{0}}=\left[\frac{\left(1+r_{f}\right)}{(1+r)}\right]^{N}
$$

Default insurance is paid each period. Therefore the $\mathrm{N}$ period version of (2a) recognises that the credit default swap $\mathrm{C}$ is a future value of an annuity.

$$
\frac{F_{1}}{S_{0}}=\left[\frac{\left(1+r_{f}\right)}{(1+r)}\right]^{N}-\left[\frac{(1+r)^{N}-1}{r}\right] \frac{C}{(1+r)^{N}}
$$

\section{Data and Methodology}

One problem encountered in examining covered interest rate parity is a lack of high quality observations on long-term interest rates the terms of which are comparable across different markets. A ready solution is the interest rate swap market. This market has evolved into one of the most important international fixed income markets. This instrument allows investors to convert a sequence of floating rate payments into a fixed stream and vice versa. The quote is always the fixed rate against the floating rate flat, i.e., pay $8 \%$ and receive LIBOR flat, and virtually all swaps are governed by the terms and conditions specified by the International Swap Dealers Association. There is a close relationship between the swap rates and the underlying national yield curve as the swap fixed rates are set as a spread off national benchmark bonds. Moreover, bid and ask prices are available so transaction costs can also be estimated. 
Therefore this paper will use the fixed interest rate on domestic and foreign swap contracts as the domestic $r$ and foreign $r_{f}$ interest rates in evaluating covered interest rate parity for long term capital markets because a) swap terms and conditions are comparable across different markets b) swaps are liquid instruments so high quality information is available even for long terms in emerging markets c) swap rates are closely related to the underlying national bond markets and reflect the interest rates available for borrowing and investment.

The data for this study is collected as of 16:30 BST from Bloomberg ${ }^{\mathrm{TM}}$. The data consists of the ask, mid and bid data for the spot and the three month and five year forward exchange rates, the US domestic and foreign fixed rates on three-month deposits and five year interest rate swaps and finally five year CDS premiums. The CDS premiums are based on a notional five-year bond of the sovereign. This paper uses a five-year horizon to examine the long-term capital market performance of covered interest rate parity because CDS and interest rate swaps are most frequently traded at that maturity. A complete set of data is collected for Brazil, Chile, Russia, South Korea and, except for CDS rates, the United Kingdom and Norway. This means the dataset consists of 18 data series for each country (15 for the UK and Norway) and including the ask, mid and bid data for the two interest rate maturities for the US, 108 data series in all.

For each country and maturity, a complete set of exchange rate, interest rate and CDS data is collected on a given day only if Bloomberg ${ }^{\mathrm{TM}}$ flags that all markets are active for that date. Bloomberg ${ }^{\text {TM }}$ defines an "active trading day" for a market as a day when there is at least one transaction in the underlying instrument. The data was collected from January 1, 2003 until October 31, 2006 thereby avoiding the unusual market conditions surrounding the credit crunch period and the virtual collapse of the sovereign CDS market. As the CDS market (and the five year currency forward market for Norway) started at different dates for each country, the number of data points available for a given country and maturity varies from as little at 211 days for Russian to as much as 836 days for the UK but in total the full dataset amounts to 5,995 observations, 2,893 for emerging markets and 1,672 for the UK and 1,430 for Norway. ${ }^{2}$ The characteristics of the emerging market data and the UK, Norway and United States data is reported in Table $2 \mathrm{a}$ and Table $2 \mathrm{~b}$ respectively. 
[Place Tables $2 \mathrm{a}$ and $2 \mathrm{~b}$ about here]

Table 2a reports that when compared to the normal distribution, the distributions of the different data series range from the typical time series properties of excess kurtosis and positive skewness for Chile's exchange rate data to negative kurtosis and negative skewness for Brazil's exchange rate data. Typically the longer the term of the data the greater the variation as measured by the standard deviation. However the interest rate data is a clear exception where typically the five-year interest rate swap data is less variable than the three-month interest rate data. Table $2 b$ reports that the UK, Norway and US interest rate data also follow this pattern. Returning to Table 2a, relative to its mean the credit default swap data displays the greatest range of all the variables followed by the five-year forward rate. The range for credit default swap data is largest for Brazil and the range for the five-year forward rate is largest for Chile.

The examination of CIRP proceeds in three steps. The first step is to evaluate standard covered interest rate parity and covered interest rate parity adjusted for credit risk using the closing daily mid price for the spot and forward exchange rates, the US and foreign interest rates and where applicable the credit default swap rates for Brazil, Chile, Russia, South Korea, Norway and the UK for three month and five-year horizons. This evaluation will give us the largest possible number of violations of covered interest rate parity, as there is no adjustment for transactions costs.

The second step corrects CIRP for transactions costs using information contained in the bid ask spread for all of the data series. Depending upon the inventory position of the market maker, transactions can occur at the extremes of the lower bid and higher ask rather than at the mid price. Therefore covered interest rate parity is calculated at the extremes of assuming all transactions work towards widening the interest rate differentials for CIRP (5a) thereby forming the lower limit for forward differentials and again by assuming all transactions work towards widening the spot forward exchange rate premium for CIRP (5b) thereby forming the upper limit for forward differentials without default insurance. Therefore, (5a) and (5b) forms the range of within which covered interest rate parity still holds. 
Lower Limit $=\frac{F_{1}^{\mathrm{B}}-\mathrm{S}_{0}^{\mathrm{A}}}{\mathrm{S}_{0}^{\mathrm{A}}}-\frac{\left(\mathrm{r}_{\mathrm{f}}^{\mathrm{A}}-\mathrm{r}^{\mathrm{B}}\right)}{\left(1+\mathrm{r}^{\mathrm{B}}\right)}$ (5a) UpperLimit $=\frac{\mathrm{F}_{1}^{\mathrm{A}}-\mathrm{S}_{0}^{\mathrm{B}}}{\mathrm{S}_{0}^{\mathrm{B}}}-\frac{\left(\mathrm{r}_{\mathrm{f}}^{\mathrm{B}}-\mathrm{r}^{\mathrm{A}}\right)}{\left(1+\mathrm{r}^{\mathrm{A}}\right)}$

In particular the superscripts A and B refer to the ask and bid prices respectively. Note that in (5a) the currency is bought forward at the lowest possible (bid) price and sold spot as the highest possible (ask) price. Meanwhile the interest rate differentials are at the highest possible values. Together the lowest possible forward premium along with the highest possible interest rate differential forms the lower limit of CIRP that is consistent with the structure of transaction cost. Inspection of (5b) reveals that the bid and ask prices work towards obtaining the highest possible forward premium and lowest possible interest rate differential that is consistent with covered interest rate parity adjusted for transactions costs.

Similarly, (6a) and (6b) represents the lower and upper limits consistent with CIRP when adjusting CIRP for the impact of credit risk as well as transactions cost. This range will be wider due to the presence of the additional credit default swap transaction.

Lower Limit $=\frac{\mathrm{F}_{1}^{\mathrm{B}}-\mathrm{S}_{0}^{\mathrm{A}}}{\mathrm{S}_{0}^{\mathrm{A}}}-\frac{\left(\mathrm{r}_{\mathrm{f}}^{\mathrm{A}}-\mathrm{r}^{\mathrm{B}}\right)-\mathrm{C}^{\mathrm{B}}}{\left(1+\mathrm{r}^{\mathrm{B}}\right)}$ (6a) Upper Limit $=\frac{\mathrm{F}_{1}^{\mathrm{A}}-\mathrm{S}_{0}^{\mathrm{B}}}{\mathrm{S}_{0}^{\mathrm{B}}}-\frac{\left(\mathrm{r}_{\mathrm{f}}^{\mathrm{B}}-\mathrm{r}^{\mathrm{A}}\right)-\mathrm{C}^{\mathrm{A}}}{\left(1+\mathrm{r}^{\mathrm{A}}\right)}(6 \mathrm{a})$

The third step is to regress explanatory factors against deviations (violations) in covered interest rate parity DCIRP after adjusting for transactions costs but without adjusting for CDS premiums to see if credit risk can provide an explanation for deviations in CIRP. This step is necessary because Duffie (1999) points out that credit default swaps only imperfectly insure against default so violations in CIRP due to credit risk can still persist even after adjusting for credit default swap premiums and transactions cost. Moreover, Blanco et al. (2005) empirically verify Duffie (1999) by finding that CDS prices are often much larger than the credit spread for corporate bonds.

Bearing this fact in mind a regressions model is run where the dependant variable is DCIRP after adjusting for transactions costs but without adjusting for CDS premiums. These DCIRP will be cases of violations of the lower (5a) and the upper limits (5b). 
This does mean that the sign of the DCIRP is ambiguous since an "increase" in DCIRP can be an increase in the "negativeness" of a violation in the lower limit (an inverse relation), or an increase in the "positiveness" of the upper limit (a direct relation). This can cause problems in interpreting the coefficients in the later regressions. For example, as explained later in detail, an increase in volatility should be associated with "an increase" in DCIRP. However, "an increase" in DCIRP could be a further leftward movement beyond the lower limit 5(a) that is mathematically a negative relation with volatility, or a further rightward movement beyond the upward limit 5(b) that is mathematically a positive relation with volatility. Therefore the dependant variable for the regression analysis is the absolute value of the DCIRP so that an "increase" in DCIRP means a movement away from covered interest rate parity in either the positive or negative direction.

The literature provides guidance as to the likely candidates for factors that can be associated with violations in CIRP. Elton et al. (2001) find that a major portion of the credit spread for corporate bonds can be explained by the Fama and French (1993) risk factors. Therefore proxies for potential sources of risk that can lead to credit loses in attempting to exploit violations in CIRP include the Fama and French factors for market risk MF, size SMB and value HML. ${ }^{3}$ However all three factors prove to be more correlated with each other than with DCIRP. Moreover later regressions showed clear evidence of high collinearity amongst these three variables so the MF is chosen as the appropriate market risk factor. ${ }^{4}$

The market factor MF represents the value weighted return of the US stock market in excess of the risk free rate. The data from this series is collected from French's data library. We expect that there is a positive correlation between returns on the stock market and the bond market so when the return in the stock market is high so too is the return in the corporate bond market. In the mean time, better returns on the stock and bond markets imply that it is less likely that the sovereign market will default on its debt obligations so deviations in covered interest rate parity DCIRP will decrease.

Apart from the Fama and French (1993) factors changes in the VIX index VIX and changes in the slope of the Treasury curve SLOPE are also chosen as proxies for credit risk. The VIX index measures the implied volatility of the near-term at-the- 
money S\&P 500 index options. The VIX index rises when uncertainty does since an increase in volatility increases option prices. Taylor (1989), Bhar et al. (2004) and Batten and Szillagyi (2010) suggest that market turbulence can be related to violations in CIRP. Therefore as the VIX index and therefore market volatility increases DCIRP increases possibly because governments are more likely to default on their debt during turbulent market conditions. The VIX data is collected from DataStream.

Estrella and Hardouvelis (1991) and Estrella and Mishkin (1997) find that increases in the slope of the term structure foreshadow improvements in real economic activity while Estrella and Mishkin (1998) find that decreases in the slope of the term structure indicates an increased likelihood of future recessions. Therefore an increase in the slope of the Treasury yield curve would foreshadow good economic conditions worldwide leading to a decrease in covered interest rate parity violations as foreign governments are less likely to default if good economic conditions are expected to occur. The slope is measured as the difference between the ten-year constant maturity Treasury yield less the three-month T-bill yield. This data is collected from the Federal Reserve Bank of New York.

Finally DCIRP will be mathematically rather than economically related to the levels of the market premium, market volatility and the term structure slope because deviations in covered interest rate parity DCIRP is a spread. Therefore the model is computed in the first differences. In summary the regression model is as follows.

$\Delta \mathrm{DCIRP}_{\mathrm{i}, \mathrm{m}, \mathrm{t}}=\beta_{0}+\beta_{1} \Delta \mathrm{MF}_{\mathrm{t}}+\beta_{2} \Delta \mathrm{VIX}_{\mathrm{t}}+\beta_{3} \Delta \mathrm{SLOPE}_{\mathrm{t}}+\varepsilon_{\mathrm{i}, \mathrm{m}, \mathrm{t}}$

where,

$\triangle \mathrm{DCIRP}_{\mathrm{i}, \mathrm{m}, \mathrm{t}}:$ change in the absolute value of the deviation in covered interest rate parity after transactions costs for country 'i $\mathrm{i}$ ” and maturity ' $\mathrm{m}$ ' at date ‘ $\mathrm{t}$ '.

$\Delta \mathrm{MF}_{\mathrm{t}}$ : change in the return on the US stock market in excess of the risk free rate at date t. $\beta_{1}$ is negative. 
$\Delta$ VIX $_{\mathrm{t}}$ : change in the VIX index level at date ' $\mathrm{t}$ '. $\beta_{2}$ is positive.

$\triangle \mathrm{SLOPE}_{\mathrm{t}}$ : change in the slope of term structure of interest rates as measured by the difference between ten year and three month constant maturity US Treasury yields at date' $t$ '. $\beta_{3}$ is negative.

\section{Numerical Analysis}

We now examine deviations in returns from covered interest rate parity evaluated at the mid transaction prices. The deviations in returns are examined twice, first without adjusting for credit risk by subtracting the right hand side of (1b) from its left hand side and second after adjusting for credit risk by subtracting the right hand side of $(2 b)$ from its left hand side. This step examines covered interest rate parity assuming that transactions costs are zero and so should provide the strictest condition on interest rate parity. The results are reported in Table 3

[Table 3 about here]

Table 3 measures the mean and standard deviation of deviations in returns from covered interest rate parity DCIRP for the entire sample period and for the first and second half sub-periods. ${ }^{5}$ If covered interest rate parity were to hold then the mean deviations in returns would be zero. A positive mean indicates that returns on foreign exchange is "too high" relative to returns on interest rates while a negative mean indicates that returns on interest rates are "too high" relative to returns on foreign exchange. If violations in covered interest rate parity were caused by credit risk, we would expect that the mean deviation in returns on covered interest parity would be negative. The foreign interest rate would include a risk premium to compensate investors for perceived credit risk and so the foreign interest rate would be "too large" relative to the US interest rate than that suggested by interest rate parity conditions alone.

Table 3 shows that the mean and the standard deviation in DCIRP without adjusting for credit default swaps increase with maturity but except for two instances are not 
statistically significant. The exceptions are both in the last half of the available data where at three months DCIRP is negative and significant for the UK and at five years DCIRP is negative and significant for Russia. The size of these violations at three months is typically very small, ranging from a fraction of a basis point for Russia and the UK, to a little more than five basis points for South Korea. At five years however, all of the emerging markets show evidence of a massive violation in covered interest rate parity where the DCIRP are at least 20 basis points for the entire period. It is interesting to note that in contrast to the UK at three months, the negative and statistically significant DCIRP for Russia at five years in the second half of the data is large and so this violation in CIRP looks economically as well as statistically significant. In contrast, the UK DCIRP is little more than a single basis point. Norway represents an intermediate case where DCIRP is above 10 basis points in the first subperiod.

Table 3 also hints that insuring apparent violations in covered interest rate parity against credit risk by using credit default swaps is liable to be ineffective in most cases. For all but Chile, column 3 of Table 3 shows that DCIRP at five years that are above 10 basis points is negative; suggesting that credit risk can explain why these larger deviations occur. However as shown in the last column of Table 3 insuring these deviations against credit risk by purchasing CDS typically creates larger DCIRP and often of the opposite sign. South Korea is an exception where negative DCIRP of more than 28 basis points are reduced to less than 8 basis points when insuring these deviations against credit risk.

Table 3 reports the "raw" DCIRP that are unadjusted for transactions cost. Many of these evident DCIRP can disappear once transactions cost incurred in order to exploit them are accounted for. Table 4 reports that DCIRP decrease once CIRP is adjusted for the impact of transactions cost and none of these deviations are statistically significant. The average DCIRP is trivially small, less than one basis point for Brazil, Chile, Russia, Norway and the UK and barely 2 basis points for South Korea at three months maturity. However, moving into longer time horizons DCIRP, although statistically insignificant, still remains high for all emerging markets, ranging from six basis points for Chile to a very large 94 basis points for Brazil. In contrast DCIRP remain trivial only for Norway and the UK. 
[Table 4 about here]

Insuring these DCIRP against credit risk via CDS is usually ineffective. After transactions costs, the CDS insured deviations are actually larger for Chile and larger and of the opposite sign for Brazil and Russia. These results are consistent with Blanco et al. (2005) who find that CDS prices are too large relative to the credit spread implying that credit risk is overpriced by CDS. South Korea is an exception however since insuring DCIRP using CDS reduces deviations of approximately 22 basis points for five years maturity to less than four basis points.

While Table 4 reports the average DCIRP after transactions and credit insurance costs one would also like information concerning the number and frequency of evident DCIRP. Table 5 addresses this gap by reporting the number and sample frequency of DCIRP after adjusting for transactions costs. The incidence of DCIRP is infrequent, less than $10 \%$ of the sample size, for Brazil, Chile, Russia and Norway at three months maturity. Surprisingly the incidence of DCIRP for the UK is nearly $20 \%$ and for South Korea nearly $40 \%$ at three months maturity. However, combined with the trivially small average size of transaction adjusted DCIRP as reported in Table 4, it is evident that covered interest rate parity holds at three months for all countries in the sample. ${ }^{6}$

On the other hand, the frequency of DCIRP is larger and sometimes very large at five years maturity all four emerging markets as well as Norway. For the emerging markets, even when insuring these DCIRP against credit risk via CDS does not materially reduce the frequency of DCIRP. Recognising that Table 4 reports that the average DCIRP is generally not small for longer maturities, one is compelled to conclude that covered interest rate parity does not hold for these emerging markets for longer terms. Meanwhile the number of violations of CIRP is less than five percent for the UK. Combined with the trivial size of these violations as reported in Table 4, it is evident that covered interest rate parity holds for the UK at five years maturity. Similarly, we conclude that CIRP holds at five years for Norway as well as the average size of violations in Table 4 are so small that any profits to be gained by trading on violations of CIRP are economically trivial. ${ }^{7}$ 
[Table 5 about here]

\section{Regression analysis}

The numerical analysis concludes that while covered interest rate parity does hold for the UK and Norway in the short and long term and for the emerging markets for the short term, it does not hold for emerging markets for longer-term maturities. Therefore we would like to explain these deviations by regressing common proxies for aspects of credit risk such as market risk premiums, volatility and default risk on the absolute value of DCIRP.

It is natural to suggest that market turbulence can be related to DCIRP (Taylor 1989), and in fact Bhar et al. (2004) and Batten and Szillagyi (2010) find statistical evidence that this is so. Moreover the regression model (7) finds that autocorrelation is sometimes present. This naturally suggests that (7) could be affected by "autocorrelation in volatility" so the first step is to test to see if ARCH effects are present in (7). When ARCH effects are present then (7) is augmented by (8) according to the procedures as established by Bollerslev (1986) and Taylor (1986). This needs to be done since standard errors are biased and inconsistent in the presence of ARCH effects. GARCH models are a particularly attractive method for correcting for ARCH errors since a GARCH model is a parsimonious representation of an infinite order ARCH model that avoids overfitting (see Brooks 2002).

Since there is little theoretical justification for anything other than first order GARCH errors a GARCH $(1,1)$ model is run when there is evidence that $\mathrm{ARCH}$ effects are present. In this case the error term in (7) is estimated as seen in (8) below.

$\sigma_{i, m, t}^{2}=\alpha_{0}+\alpha_{1} \mu_{i, m, t-1}^{2}+\beta \sigma_{i, m, t-1}^{2}$

Specifically the volatility of the error term in (7) depends upon a constant $\alpha_{0}$, information on last period's volatility $\alpha_{1} \mu_{\mathrm{i}, \mathrm{m}, \mathrm{t}-1}^{2}$ and the fitted variance from the previous period $\beta \sigma_{i, m, t-1}^{2}$. GARCH $(1,1)$ models are non-linear and so are estimated 
via maximum likelihood. If there is no evidence of $\mathrm{ARCH}$ effects or if there are estimation problems with GARCH $(1,1)$ then $(7)$ is run using OLS and robust standard errors as suggested by White (1980) and if autocorrelation is present then (7) is run using an autocorrelation and heteroscedasticity consistent estimate according to the Newey and West (1987) procedure.

The results of these econometric procedures are presented in Table $6 .{ }^{8}$ The first row for each country and maturity reports the results of two chi-square tests, the first tests whether the underlying OLS model is statistically significant and the second tests whether the error term in (7) displays ARCH effects. If the ARCH effects test is significant, (7) is augmented by a GARCH $(1,1)$ model for the error term and the results report values for the coefficients of the constant $\alpha_{0}$, the lagged volatility $\alpha_{1}$ and last period's fitted variance $\beta$ for the error structure according to (8). However we find that the GARCH estimates are not valid for Russia at three months and for Brazil at five years. Specifically GARCH discovers a non-stationary unconditional variance for Russia because $\alpha_{1}+\beta>1$ and GARCH violate the non negativity constraint for Brazil as $\beta<0$. Therefore we report Newey and West (1987) estimates for the DCIRP for Russia at three months and for Brazil at five years instead.

The coefficients for the market factor MF, the VIX index and for the slope of the US term structure SLOPE are statistically significant and of the expected sign in six instances. Notice that at five years maturity for Brazil and South Korea, where Table 4 reports the largest negative DCIRP after transactions costs (but not including default insurance) and Table 5 reports an extraordinary large percentage of violations in covered interest rate parity ( 85 and $71 \%$ respectively), we find evidence that five of the six coefficients associated with aspects of credit risk is statistically significant. In other words, where there is strong evidence of violations in covered interest rate parity, there is the strongest evidence that DCIRP is related to aspects of credit risk.

\section{Summary and Conclusions}

This paper examines deviations in covered interest rate parity for Brazil, Chile, Russia, South Korea, Norway and the UK. While there is little evidence of any 
violation in covered interest rate parity at three months maturity, the size and frequency of violations in covered interest rate volatility increase with maturity for the four emerging markets. This study concludes that covered interest rate parity holds for the UK and Norway for short and long-term capital markets but holds for the emerging markets only for the short term.

Insuring against default using credit default swaps did not seem to materially affect these results. When insuring DCIRP with CDS the violation in covered interest rate parity often merely change sign from a large negative to a large positive thereby suggesting that CDS overprice credit risk. However, this study still finds that these violations can be attributed to aspects of credit risk as the largest violations in covered interest rate parity in the emerging markets are associated with factors related to credit risk. Overall this paper finds that there are indeed violations in covered interest rate parity in the long-term capital markets but only for emerging markets. Moreover the source of these violations is likely to be credit risk rather than the size of the economy or transactions costs. 


\section{References}

Al-Loughani, N., \& Moosa, I., 2000. Covered interest parity and the relative effectiveness of forward and money market hedging. Applied Economics Letters 7, 673-675.

Aliber, R., 1973. The interest rate parity theorem: a reinterpretation. Journal of Political Economy 81, 1451-1459.

Baba, N., \& Packer F., 2009. Interpreting deviations from covered interest parity during the financial market turmoil of 2007 08. Journal of Banking and Finance 33, 1953-1962.

Batten, J.A., Chan, W., Chung, H., \& Szilagyi P.G. 2011. The dynamics of arbitrage: evidence from the yen forward markets. Hong Kong University of Science \& Technology working paper series.

Batten, J. A., \& Szillagyi P.G., 2010. Is covered interest parity arbitrage extinct? Evidence from the spot Usd/Yen. Applied Economics Letters 17, 283-287.

Bhar, R., Kim S., \& Pham T., 2004. Exchange rate volatility and its impact on the transaction costs of covered interest rate parity. Japan and the World Economy 16, 503-525. 
Blanco, R., Brennan S., \& March I., 2005. An empirical analysis of the dynamic relation between investment-grade bonds and credit default swaps. The Journal of Finance 60, 2255-2281.

Bollerslev, T., 1986. Generalized autoregressive conditional heteroskedasticity. Journal of Econometrics 31, pp. 307-328.

Brooks, C., 2002. Introductory Econometrics for Finance, Cambridge University Press, Cambridge.

Duffie, D.,1999. Credit swap valuation. Financial Analyst Journal 55, 73-87.

Elton, E., Gruber M. Agrawal D., \& Mann C., 2001. Explaining the rate of spread on corporate bonds. Journal of Finance 56, 247-277.

Estrella, A., \& Hardouvelis G., 1991. The term structure as a predictor of real economic activity. Journal of Finance 46, 555-576.

Estrella, A., \& Mishkin F., 1997. The predictive power of the term structure of interest rates in europe and the United States: Implications for the European central bank. European Economic Review 41, 1375-1401.

Estrella, A., \& Mishkin F., 1998. Predicting U.S. recessions: Financial variables as leading indicators. Review of Economics and Statistics 80, 45-61. 
Fama, F., \& French K., 1993. Common risk factors in the returns on stocks and bonds. Journal of Financial Economics 33, pp 3-56.

Fletcher, D., \& Taylor L., 1996. 'Swap' covered interest parity in long-date capital markets. Review of Economics and Statistics 78, 530-538.

Fong, W., Valente, G., Fung J., 2010. Covered interest rate profits: The role of liquidity and credit risk. Journal of Banking and Finance 34, 1098-1107.

Levi, M., 1977.Taxation and 'abnormal' international capital flows. Journal of Political Economy 85, 635-646.

Louis, H. Blenman L., \& Thatcher J., 1999. Interest rate parity and the behavior of the bid-ask spread. Journal of Financial Research 22, 189-206.

Newey, W., \& West K., 1987. A simple, positive semi-definite, heteroskedasticity and autocorrelation consistent covariance matrix. Econometrica 55, 703-708.

Stroble, F., 2001. International tax arbitrage, tax evasion and interest parity conditions. Research in Economics 55, 413-427.

Taylor, S., (1986). Forecasting the volatility of currency exchange rates. International Journal of Forecasting 3, 159-170. 
Taylor, M., 1987. Covered interest parity: A high-frequency, high quality data study. Economica 54, 429-438.

Taylor, M., 1989. Covered interest arbitrage and market turbulence. Economic Journal 99, 376-391.

White, H., 1980. Heteroskedasticity consistent covariance matrix estimator and direct test for heteroskedasticity. Econometrica 48, $817-838$. 


\section{Table 1}

This table reports the credit rating history of Brazil, Chile, Russia, South Korea, Norway and the United Kingdom UK from January 1, 2003 to October 31, 2006 according to Standard \& Poor. Standard \& Poor's credit system ranks AAA as the highest possible credit rating and $\mathrm{AA}, \mathrm{A}$ and $\mathrm{BBB}$ are investment grade whereas $\mathrm{BB}$ and $\mathrm{B}$ are below investment grade. Modifiers of + and - indicate that the sovereign are at the upper and lower end respectively of the broad rating class.

\begin{tabular}{lllllll}
\hline Rating date & Brazil & Chile & Russia & $\begin{array}{l}\text { South } \\
\text { Korea }\end{array}$ & Norway & UK \\
\hline January 1, 2003 & B+ & A- & BB & A- & AAA & AAA \\
January 14, 2004 & B+ & A & BB & A- & AAA & AAA \\
January 27, 2004 & B+ & A & BB+ & A- & AAA & AAA \\
September 17, 2004 & BB- & A & BB+ & A- & AAA & AAA \\
January 31,2005 & BB- & A & BBB- & A- & AAA & AAA \\
July 27, 2005 & BB- & A & BBB- & A & AAA & AAA \\
December 15, 2005 & BB- & A & BBB & A & AAA & AAA \\
February 28, 2006 & BB & A & BBB & A & AAA & AAA \\
September 4, 2006 & BB & A & BBB + & A & AAA & AAA \\
\hline
\end{tabular}


Table 2a

Moving to the right from column two, this table reports the sample statistics for the spot exchange rate, the three month and five year forward exchange rates, the three month and five year interest rates and the five year credit default swap rates for Brazil, Chile, Russia and South Korea. Exchange rate data is in foreign currency units per United States Dollar, interest rates are in percent and all CDS data are in basis points.

\begin{tabular}{|c|c|c|c|c|c|c|}
\hline Brazil & Spot FX & $F R 3 M O$ & FR $5 Y R$ & $I R 3 M O$ & $S W 5 Y R$ & CDS 5YR \\
\hline Mean & 2.69 & 2.78 & 4.71 & 15.38 & 17.05 & 409.31 \\
\hline Median & 2.82 & 2.91 & 4.85 & 15.65 & 17.03 & 405.00 \\
\hline Std Dev & 0.33 & 0.35 & 1.04 & 1.80 & 2.10 & 194.67 \\
\hline Kurtosis & -0.94 & -0.89 & -0.88 & -1.05 & -0.14 & -0.79 \\
\hline Skewness & -0.65 & -0.67 & -0.24 & -0.25 & 0.09 & 0.06 \\
\hline Range & 1.15 & 1.23 & 3.73 & 6.85 & 10.59 & 747.93 \\
\hline Minimum & 2.06 & 2.11 & 3.03 & 12.00 & 12.73 & 108.89 \\
\hline Maximum & 3.21 & 3.34 & 6.76 & 18.85 & 23.32 & 856.82 \\
\hline No Obs. & 325 & 325 & 325 & 325 & 325 & 325 \\
\hline \multicolumn{7}{|l|}{ Chile } \\
\hline Mean & 546.51 & 547.27 & 588.68 & 4.78 & 6.24 & 23.37 \\
\hline Median & 537.13 & 537.16 & 579.40 & 5.25 & 6.43 & 21.13 \\
\hline Std Dev & 33.82 & 34.28 & 41.89 & 0.97 & 0.51 & 12.43 \\
\hline Kurtosis & 8.62 & 8.82 & 19.78 & 0.59 & 1.00 & 48.49 \\
\hline Skewness & 2.50 & 2.53 & 3.83 & -1.24 & -1.01 & 6.87 \\
\hline Range & 207.45 & 209.74 & 323.95 & 3.78 & 3.54 & 99.94 \\
\hline Minimum & 510.70 & 510.85 & 547.10 & 1.91 & 3.65 & 17.56 \\
\hline Maximum & 718.15 & 720.59 & 871.05 & 5.69 & 7.19 & 117.50 \\
\hline No Obs & 372 & 356 & 372 & 356 & 372 & 372 \\
\hline \multicolumn{7}{|l|}{ Russia } \\
\hline Mean & 27.39 & 27.35 & 28.60 & 4.34 & 6.41 & 58.57 \\
\hline Median & 27.05 & 27.00 & 27.92 & 4.35 & 6.40 & 57.50 \\
\hline Std Dev & 0.67 & 0.72 & 1.20 & 0.79 & 0.23 & 8.05 \\
\hline Kurtosis & -0.85 & -0.80 & 0.08 & 0.72 & -0.88 & -0.37 \\
\hline Skewness & 0.74 & 0.73 & 1.06 & 0.25 & 0.10 & 0.65 \\
\hline Range & 2.17 & 2.40 & 4.37 & 5.05 & 1.18 & 35.00 \\
\hline Minimum & 26.66 & 26.52 & 27.35 & 2.31 & 5.82 & 44.50 \\
\hline Maximum & 28.83 & 28.92 & 31.72 & 7.36 & 7.00 & 79.50 \\
\hline No Obs & 211 & 211 & 211 & 211 & 211 & 211 \\
\hline \multicolumn{7}{|c|}{ South Korea } \\
\hline Mean & 1040.66 & 1041.83 & 1036.25 & 4.07 & 4.66 & 41.71 \\
\hline Median & 1016.50 & 1016.00 & 1007.55 & 4.06 & 4.74 & 31.67 \\
\hline Std Dev & 87.93 & 92.24 & 113.42 & 0.42 & 0.39 & 26.80 \\
\hline Kurtosis & -0.60 & -0.59 & -0.75 & -1.22 & 0.42 & 6.46 \\
\hline Skewness & 0.84 & 0.86 & 0.77 & 0.02 & -0.87 & 2.34 \\
\hline Range & 330.15 & 341.95 & 383.95 & 1.63 & 2.02 & 163.83 \\
\hline Minimum & 927.80 & 924.80 & 894.90 & 3.43 & 3.34 & 22.00 \\
\hline Maximum & 1257.95 & 1266.75 & 1278.85 & 5.06 & 5.36 & 185.83 \\
\hline No Obs & 560 & 533 & 560 & 533 & 560 & 560 \\
\hline
\end{tabular}


Table 2b

Moving to the right from column two, this table reports the sample statistics for the spot exchange rate, the three month and five year forward exchange rates and the three month interest rate and five year swap interest rate for the United Kingdom. Panel two reports the sample statistics for the three-month and five year interest rates for the United States. Exchange rate data is in United States Dollars per Pound Sterling and interest data are in percent.

\begin{tabular}{|c|c|c|c|c|c|}
\hline UK & Spot FX & $F R 3 M O$ & $F R 5 Y R$ & $I R 3 M O$ & SW 5YR \\
\hline Mean & 1.79 & 1.78 & 1.74 & 4.40 & 4.85 \\
\hline Median & 1.80 & 1.80 & 1.77 & 4.53 & 4.88 \\
\hline Std Dev & 0.09 & 0.10 & 0.12 & 0.47 & 0.37 \\
\hline Kurtosis & -0.33 & -0.29 & -0.70 & -0.38 & -0.05 \\
\hline Skewness & -0.69 & -0.71 & -0.52 & -0.94 & -0.40 \\
\hline Range & 0.40 & 0.40 & 0.45 & 1.83 & 1.88 \\
\hline Minimum & 1.55 & 1.54 & 1.48 & 3.26 & 3.77 \\
\hline Maximum & 1.95 & 1.94 & 1.92 & 5.09 & 5.65 \\
\hline No Observations & 836 & 836 & 836 & 836 & 836 \\
\hline \multicolumn{6}{|l|}{ Norway } \\
\hline Mean & 6.62 & 6.62 & 6.56 & 2.53 & 4.11 \\
\hline Median & 6.59 & 6.57 & 6.33 & 2.27 & 4.02 \\
\hline Std Dev & 0.34 & 0.36 & 0.59 & 0.95 & 0.58 \\
\hline Kurtosis & -0.13 & -0.25 & -0.38 & 6.06 & 0.89 \\
\hline Skewness & 0.46 & 0.50 & 0.80 & 2.46 & 1.05 \\
\hline Range & 1.64 & 1.71 & 3.12 & 4.71 & 2.75 \\
\hline Minimum & 6.01 & 5.98 & 4.92 & 1.62 & 3.29 \\
\hline Maximum & 7.65 & 7.69 & 8.04 & 6.33 & 6.04 \\
\hline No Observations & 715 & 715 & 715 & 715 & 715 \\
\hline \multicolumn{6}{|l|}{ United States } \\
\hline Mean & N/A & N/A & N/A & 4.78 & 6.24 \\
\hline Median & N/A & N/A & N/A & 5.25 & 6.43 \\
\hline Std Dev & N/A & N/A & N/A & 0.97 & 0.51 \\
\hline Kurtosis & N/A & N/A & N/A & 0.59 & 1.00 \\
\hline Skewness & N/A & N/A & N/A & -1.24 & -1.01 \\
\hline Range & N/A & N/A & N/A & 3.78 & 3.54 \\
\hline Minimum & N/A & N/A & N/A & 1.91 & 3.65 \\
\hline Maximum & N/A & N/A & N/A & 5.69 & 7.19 \\
\hline No Observations & N/A & N/A & N/A & 356 & 372 \\
\hline
\end{tabular}


Table 3

This table shows the mean and standard deviation SD of deviations in covered interest rate parity DCIRP, measured in basis points on an annualised basis and evaluated at the mid transaction prices, for the time horizon of three months and five years. For the five-year horizon DCIRP is also evaluated after purchasing default insurance using credit default swaps CDS. These statistics are reported for the overall sample, (all) and for the first half (first) and second half (last) of the sample.

\begin{tabular}{lrrr}
\hline & Three Months & Five Years & Five Years \\
After CDS
\end{tabular}

*** Statistically significant at the $1 \%$ level 


\section{Table 4}

This table examines the influence of transactions costs in explaining deviations in covered interest rate parity DCIRP. DCIRP is measured as the amount by which the covered interest rate parity condition is above or below the boundaries established by the bid and ask prices for spot and forward currency, interest rate and (if applicable) credit default swap transactions. The mean and standard deviation SD of DCIRP after transactions costs, measured in basis points on an annualised basis, are reported for the time horizon of three months and five years. The column including the label "after CDS" represent remaining DCIRP after accounting for the additional transactions cost incurred in attempting to insure covered interest rate parity discrepancies for credit risk. These statistics are reported for the overall sample, (all) and for the first half (first) and second half (last) of the sample.

\begin{tabular}{|c|c|c|c|c|c|c|}
\hline & \multicolumn{3}{|c|}{ Brazil } & \multicolumn{3}{|c|}{ Chile } \\
\hline & $\begin{array}{l}\text { Three } \\
\text { Months }\end{array}$ & $\begin{array}{l}\text { Five } \\
\text { Years }\end{array}$ & $\begin{array}{l}\text { Five Years } \\
\text { After CDS }\end{array}$ & $\begin{array}{l}\text { Three } \\
\text { Months }\end{array}$ & $\begin{array}{l}\text { Five } \\
\text { Years }\end{array}$ & $\begin{array}{l}\text { Five Years } \\
\text { After CDS }\end{array}$ \\
\hline $\begin{array}{l}\text { Mean all } \\
\text { Mean }\end{array}$ & 0.18 & -93.96 & 107.28 & -0.03 & 5.79 & 12.04 \\
\hline $\begin{array}{l}\text { First } \\
\text { Mean }\end{array}$ & 0.45 & -131.24 & 143.43 & -0.08 & -2.97 & 0.29 \\
\hline Last & -0.09 & -56.45 & 70.92 & 0.02 & 14.56 & 23.78 \\
\hline SD all & 3.54 & 168.38 & 167.05 & 0.31 & 24.77 & 22.27 \\
\hline SD First & 3.68 & 213.74 & 203.03 & 0.38 & 24.53 & 3.30 \\
\hline SD Last & 3.39 & $\begin{array}{r}90.91 \\
\text { Russia }\end{array}$ & 109.68 & 0.21 & $\begin{array}{r}21.78 \\
\text { South K}\end{array}$ & 26.57 \\
\hline $\begin{array}{l}\text { Mean all } \\
\text { Mean }\end{array}$ & -0.16 & -6.85 & 13.70 & -1.78 & -22.25 & 3.75 \\
\hline $\begin{array}{l}\text { First } \\
\text { Mean }\end{array}$ & -0.72 & -6.13 & 23.72 & -2.10 & -39.52 & 0.83 \\
\hline Last & 0.39 & -7.56 & 3.78 & -1.47 & -4.98 & 6.68 \\
\hline SD all & 4.47 & 11.81 & 20.62 & 6.98 & 32.24 & 11.10 \\
\hline SD First & 4.95 & 13.69 & 24.77 & 8.95 & 37.58 & 12.21 \\
\hline SD Last & 3.86 & $\begin{array}{r}9.62 \\
\text { Norway }\end{array}$ & 6.53 & 4.20 & $\begin{array}{r}8.40 \\
\text { UK }\end{array}$ & 8.99 \\
\hline $\begin{array}{l}\text { Mean all } \\
\text { Mean }\end{array}$ & -0.28 & 0.24 & $\begin{array}{l}\text { N/A } \\
\text { N/A }\end{array}$ & 0.04 & -0.07 & $\begin{array}{l}\text { N/A } \\
\text { N/A }\end{array}$ \\
\hline $\begin{array}{l}\text { First } \\
\text { Mean }\end{array}$ & -0.55 & -0.96 & N/A & 0.07 & 0.04 & N/A \\
\hline Last & -0.01 & 1.44 & & 0.02 & -0.17 & \\
\hline SD all & 5.09 & 4.75 & N/A & 1.53 & 4.86 & N/A \\
\hline SD First & 7.19 & 2.93 & N/A & 2.15 & 6.53 & N/A \\
\hline SD Last & 0.06 & 5.81 & N/A & 0.26 & 2.14 & N/A \\
\hline
\end{tabular}


Table 5

This table reports the number of times $\mathrm{T}$ a trader could make a profit, after accounting for transactions costs, by exploiting deviations in covered interest rate parity from January 1, 2003 to October 31, 2006. Only those observations for dates when Bloomberg flags all instruments as being active are examined. These statistics are reported for the overall sample, (all) and for the first half (first) and second half (last) of the sample.

\begin{tabular}{|c|c|c|c|c|c|}
\hline & \multicolumn{2}{|c|}{ Three Months } & \multicolumn{3}{|c|}{ Five Years } \\
\hline & $N$ & T Without & $N$ & T Without & \\
\hline & & $C D S$ & & $C D S$ & $T$ With $C D S$ \\
\hline Brazil (All) & 325 & 21 & 325 & 278 & 217 \\
\hline (First) & 163 & 5 & 163 & 128 & 114 \\
\hline (Last) & 162 & 16 & 162 & 150 & 103 \\
\hline$\%$ (All) & N/A & 6.46 & N/A & 85.54 & 66.77 \\
\hline$\%$ (First) & N/A & 3.07 & N/A & 78.53 & 69.94 \\
\hline$\%$ (Last) & N/A & 9.88 & N/A & 92.59 & 63.58 \\
\hline Chile (All) & 356 & 12 & 372 & 107 & 139 \\
\hline (First) & 178 & 10 & 186 & 10 & 4 \\
\hline (Last) & 178 & 2 & 186 & 97 & 135 \\
\hline$\%$ (All) & N/A & 3.37 & N/A & 28.76 & 37.37 \\
\hline$\%$ (First) & N/A & 5.62 & N/A & 5.35 & 2.14 \\
\hline$\%$ (Last) & N/A & 1.12 & N/A & 51.87 & 72.19 \\
\hline Russia (All) & 211 & 19 & 211 & 108 & 115 \\
\hline (First) & 106 & 12 & 106 & 44 & 77 \\
\hline (Last) & 105 & 7 & 105 & 64 & 38 \\
\hline$\%$ (All) & N/A & 9.00 & N/A & 51.18 & 54.50 \\
\hline$\%$ (First) & N/A & 11.32 & N/A & 41.51 & 72.64 \\
\hline$\%$ (Last) & N/A & 6.67 & N/A & 60.95 & 36.19 \\
\hline South Korea & 533 & 207 & 560 & 401 & 333 \\
\hline (First) & 266 & 77 & 280 & 247 & 163 \\
\hline (Last) & 267 & 130 & 280 & 154 & 170 \\
\hline$\%(\mathrm{All})$ & N/A & 38.84 & N/A & 71.61 & 59.46 \\
\hline$\%$ (First) & N/A & 28.95 & N/A & 88.21 & 58.21 \\
\hline$\%$ (Last) & N/A & 48.69 & N/A & 55.16 & 60.50 \\
\hline Norway (All) & 715 & 19 & 715 & 195 & N/A \\
\hline (First) & 358 & 15 & 358 & 68 & N/A \\
\hline (Last) & 357 & 4 & 357 & 127 & N/A \\
\hline$\%$ (All) & N/A & 2.66 & N/A & 27.27 & N/A \\
\hline$\%$ (First) & N/A & 4.19 & N/A & 18.99 & N/A \\
\hline$\%$ (Last) & N/A & 1.12 & N/A & 35.57 & N/A \\
\hline UK (All) & 836 & 153 & 836 & 38 & N/A \\
\hline (First) & 418 & 72 & 418 & 20 & N/A \\
\hline (Last) & 418 & 81 & 418 & 18 & N/A \\
\hline$\%$ (All) & N/A & 18.30 & N/A & 4.55 & N/A \\
\hline$\%$ (First) & N/A & 17.22 & N/A & 4.78 & N/A \\
\hline$\%$ (Last) & N/A & 19.38 & N/A & 4.31 & N/A \\
\hline
\end{tabular}




\section{Table 6}

This table reports the results of regressing changes in the Fama and French (1993) market factor MF, the Vix index VIX and the US yield curve SLOPE on deviations in covered interest rate parity after transactions costs. The first chi-square statistic reports the results of the test whether the OLS version of the regression is statistically significant; the second chi-square statistic reports the results of the test whether autoregressive conditional heteroskedastic errors are present. If significant, a nonlinear GARCH $(1,1)$ model is estimated rather than an OLS model to correct for first order autocorrelation and heteroskedastic errors.

\begin{tabular}{|c|c|c|c|c|}
\hline & \multicolumn{2}{|c|}{ Three Month: $D F=316$} & \multicolumn{2}{|c|}{ Five Year: $D F=316$} \\
\hline Brazil & $\chi(3)=25.7^{* * *}$ & $\chi(5)=129.7^{* * *}$ & $\chi(3)=12.1^{* *}$ & $\begin{array}{l}\text { Non negative } \\
\text { constraint } \\
\text { violated }\end{array}$ \\
\hline Parameter & Coef. & Std Err & Coef. & Std Err \\
\hline Constant & 0.0047 & 0.0033 & 0.0016 & 0.0475 \\
\hline MF & $-0.0735^{*}$ & 0.0385 & $-1.3310^{*}$ & 0.8074 \\
\hline VIX & -0.0013 & 0.0018 & $0.1377 *$ & 0.0786 \\
\hline SLOPE & -0.0322 & 0.0343 & $-1.4083 *$ & 0.8395 \\
\hline$\alpha_{0}$ & $0.0012 * * *$ & 0.0000 & N/A & N/A \\
\hline$\alpha_{1}$ & $-0.0030 * *$ & 0.0014 & N/A & N/A \\
\hline$\beta$ & $0.5892 * * *$ & 0.0428 & N/A & N/A \\
\hline & \multicolumn{2}{|c|}{ Three Month: $D F=347$} & \multicolumn{2}{|c|}{ Five Year: $D F=367$} \\
\hline Chile & $\chi(3)=1.5$ & $\chi(5)=98.8^{* * * *}$ & $\chi(3)=3.7$ & $\chi(5)=0.8$ \\
\hline Parameter & Coef. & Std Err & Coef. & Std Err \\
\hline Constant & 0.0004 & 0.0010 & 0.0104 & 0.0473 \\
\hline $\mathrm{MF}$ & 0.0085 & 0.0130 & -0.7850 & 0.5287 \\
\hline VIX & 0.0015 & 0.0014 & 0.0312 & 0.0328 \\
\hline SLOPE & -0.0018 & 0.0038 & -0.5608 & 0.4603 \\
\hline$\alpha_{0}$ & 0.0001 & 0.0001 & N/A & N/A \\
\hline$\alpha_{1}$ & $0.2204 * * *$ & 0.0050 & N/A & N/A \\
\hline \multirow[t]{2}{*}{$\beta$} & $0.1543 * * *$ & 0.0020 & N/A & $\mathrm{N} / \mathrm{A}$ \\
\hline & \multicolumn{2}{|c|}{ Three Month: $D F=202$} & \multicolumn{2}{|c|}{ Five Year: $D F=202$} \\
\hline Russia & $\chi(3)=1.0$ & $\begin{array}{r}\text { Non-stationary } \\
\text { variance }\end{array}$ & $\chi(3)=2.1$ & $\chi(5)=12.6^{* *}$ \\
\hline Parameter & Coef. & Std Err & Coef. & Std Err \\
\hline Constant & -0.0017 & 0.0053 & 0.0046 & 0.0051 \\
\hline MF & 0.3186 & 0.2360 & -0.1976 & 0.1860 \\
\hline VIX & -0.0067 & 0.0122 & 0.0031 & 0.0020 \\
\hline SLOPE & 0.0051 & 0.1820 & -0.1364 & 0.1487 \\
\hline$\alpha_{0}$ & N/A & N/A & $0.0009^{*}$ & 0.0005 \\
\hline$\alpha_{1}$ & N/A & N/A & $0.3882^{* * *}$ & 0.1037 \\
\hline \multirow[t]{2}{*}{$\beta$} & N/A & N/A & $0.6239^{* * *}$ & 0.2245 \\
\hline & \multicolumn{2}{|c|}{ Three Month: $D F=524$} & \multicolumn{2}{|c|}{ Five Year: $D F=549$} \\
\hline South Korea & $\chi(3)=6.2 *$ & $\chi(5)=96.9^{* * * *}$ & $\chi(3)=10.4^{*}$ & $\chi(5)=24.7^{*}$ \\
\hline Parameter & Coef. & Std Err & Coef. & Std Err \\
\hline Constant & 0.0038 & 0.0034 & 0.0029 & 0.0022 \\
\hline $\mathrm{MF}$ & 0.1159 & 0.1065 & $-0.5208^{* * *}$ & 0.1225 \\
\hline VIX & 0.0015 & 0.0031 & -0.0028 & 0.0046 \\
\hline SLOPE & 0.0761 & 0.0921 & $-0.3743^{* * *}$ & 0.1322 \\
\hline$\alpha_{0}$ & 0.0006 & 0.0004 & 0.0001 & 0.0002 \\
\hline$\alpha_{1}$ & $0.3708^{* *}$ & 0.1193 & $0.9497^{* * *}$ & 0.1395 \\
\hline$\beta$ & 0.6851 & 0.5611 & 0.0391 & 0.1306 \\
\hline
\end{tabular}

$* * *$ Significant at the $1 \%$ level, **significant at the 5\% level, *significant at the $10 \%$ level. 


\footnotetext{
${ }^{1}$ Deviations in covered interest rate parity around the dates that Standard \& Poor and Moodys upgraded the sovereigns are examined. There was no evidence that deviations in covered interest rate parity are affected by these rating upgrades. Moodys rating changes are very similar to Standard and Poor's so for the sake of brevity Moods ratings history of the sovereigns are not reported.

${ }^{2}$ Specifically the start dates for the UK and South Korea data is January 2, 2003, for Norway, November 10, 2003, for Chile June 4, 2003, for Brazil November 10, 2003 and lastly, for Russian November 23, 2005.

${ }^{3}$ The size factor (Small Minus Big) is the return from investing in a portfolio of small firms in excess of the return from investing in a portfolio of big firms. The value factor (High Minus Low) is the return from investing in high book to market value firms in excess of the returns from investing in a portfolio of low book to market value firms. The idea is that the empirical anomalies of excess returns in small firms and firms with high book to market capitalisation ratios that can not be explained by the capital asset pricing model are actually proxing for priced risk factors.

${ }^{4}$ The correlation table is omitted for the sake of brevity. It is available from the author upon request. Also, there is still some controversy concerning precisely what source of systematic risk is being proxied by SMB and HML whereas there is a consensus that MF measures the systematic risk of investing in the market portfolio. To avoid any possible confusion concerning the interpretation of the results the MF is used.

${ }^{5}$ The sample cannot be split into equal sub-periods in calendar time as the activity in different emerging markets varied by time period. For example, the Russian five-year forward exchange market was dormant for all of 2003 and 2004 and only became active in late August 2005. Meanwhile the South Korean five-year forward exchange market was active through out most months of the entire sample period, from January 1, 2003 to October 312006.

${ }^{6}$ This is particularly true for the UK since the size of the DCIRP is typically less than one half of a basis point and can be a result of rounding. The economic consequence suggests that for every $\$ 1$ million transaction, an investor could earn less than $\$ 50$.

${ }^{7}$ A deviation of a little more than one basis point with a $20 \%$ violation is still economically trivial because a trader can only make about $\$ 100$ a week for trades of $\$ 1$ million. Additionally we repeated the GARCH regression analysis as reported in Table 6 for Norway and we could not find any proxy for credit risk that is even remotely significant in explaining the many, but small deviations in covered interest rate parity.

${ }^{8}$ UK and Norway are not included in Table 6 as there is no evidence of violation in covered interest rate parity.
} 